Received Date : 01-Jul-2016

Revised Date : 14-Sep-2016

Accepted Date : 11-Oct-2016

Article type : Original Article

\title{
Carers' views of topical-corticosteroid use in childhood eczema: a qualitative study of online discussion forums
}

Running head: Carers' views of topical-corticosteroid use in childhood eczema

E. Teasdale ${ }^{1}$, I. Muller ${ }^{1,2}$ and M. Santer ${ }^{1}$

${ }^{1}$ Primary Care and Population Science, Faculty of Medicine, University of Southampton, Southampton, UK

${ }^{2}$ Academic Unit of Psychology, Faculty of Social and Human Sciences, University of Southampton, Southampton, UK

Corresponding author: Dr Emma Teasdale PhD

E-mail: e.j.teasdale@soton.ac.uk

Key words (qualitative, discussion forum, self-management, online support group, eczema, topicalcorticosteroids, and parents/carers)

Funding source: None

Conflicts of interest: The authors have no conflicts of interest to declare.

This article has been accepted for publication and undergone full peer review but has not been through the copyediting, typesetting, pagination and proofreading process, which may lead to differences between this version and the Version of Record. Please cite this article as doi: $10.1111 /$ bjd.15130

This article is protected by copyright. All rights reserved. 


\section{What's already known about this topic?}

- The main reason for treatment failure in childhood eczema is thought to be non-adherence to treatments, mainly topical-corticosteroids and emollients.

- Despite expert consensus about the effectiveness and safety of topical-corticosteroids (if used correctly) previous research has revealed concern about their use amongst parents/carers.

\section{What does this study add?}

- We found diverse concerns around the use of topical-corticosteroids amongst posts on online forums.

- There was widespread confusion, particularly around potency of different products, duration of use and safety, for instance of use on the face.

- Parents/carers value the experiential advice and support of online forum users to try to resolve offline knowledge deficits after consultation or confusion following conflicting offline advice.

\section{What are the clinical implications of the work?}

- This study highlights that people seeking eczema information in online forums are likely to find advice with potentially negative as well as positive impacts.

- Widespread confusion expressed online suggests the need for clear, consistent advice about topical-corticosteroids, including signposting parents/carers towards reliable, evidencebased resources.

- Further research is needed to find effective ways of communicating with parents/carers and to develop resources to support them if questions arise after the consultation.

This article is protected by copyright. All rights reserved. 


\section{SUMMARY}

Background: Childhood eczema is very common and can have substantial impact on quality of life. One of the main treatments is topical-corticosteroids, but these are often under-used by parents/carers for reasons that include concerns about safety.

Objectives: To explore understandings and concerns about topical-corticosteroids amongst parents/carers of children with eczema who had posted messages in online forums.

Methods: A qualitative study of messages and their resultant discussions about topicalcorticosteroids for childhood eczema posted by parents/carers on two UK-based discussion forums.

Results: Ninety-five forum users involved in 27 discussions relating to topical-corticosteroid use in childhood eczema were identified dating from 2003-2015. Analysis of discussions highlighted three themes: 1) diverse beliefs about the use of topical-corticosteroids, 2) uncertainty and confusion about using/applying topical corticosteroids, 3) seeking to resolve conflicting advice received offline and advice on navigating health services. People expressed a general sense of cautiousness about topical-corticosteroids, wide-ranging concerns and considerable confusion, for instance about potency or safe duration of use. They sought advice from other forum users who they perceived as having experiential expertise. Some posts attempted to reassure that topical-corticosteroids were safe if used correctly, but overall the discussions seemed likely to amplify existing concerns.

Conclusions: Given the prevalence of concerns and uncertainties about topical-corticosteroids, signposting parents/carers of children with eczema towards detailed, credible information about how to use topical-corticosteroids safely would be beneficial. In the absence of such information, parents/carers are likely to turn to online discussion forums where, although much useful support and advice can be found, the credibility of advice cannot be assured.

\section{INTRODUCTION}

Eczema is very common, affecting over $20 \%$ of children aged 5 years or younger at some point. ${ }^{12}$ It can have a substantial impact on quality of life and cause significant distress to children and their families because of rashes, itching and sleep disturbance. ${ }^{3}$ Research from secondary care suggests that the impact on quality of life in children with severe eczema is second only to cerebral palsy, with greater impact than for asthma or diabetes. ${ }^{4}$

The main treatments for eczema are emollients and topical-corticosteroids but consensus guidelines suggest that poor treatment adherence is the main cause of treatment failure. ${ }^{5}$ Reasons for poor

This article is protected by copyright. All rights reserved. 
adherence include child refusal, therapy being time intensive or incomplete understanding of treatments. ${ }^{67}$ Despite professional consensus that topical-corticosteroids are safe if used correctly (summarised in Box 1), research has found widespread 'steroid phobia' amongst parents/carers, forming a barrier to effective eczema care. ${ }^{8-10}$ Although 'steroid phobia' has been recognised for some years, there is relatively little qualitative research exploring the nature of parents/carers' concerns about topical-corticosteroids.

\section{[insert box 1]}

Of the qualitative studies that have touched on views of topical-corticosteroids, one found that people with eczema said they would prefer to manage eczema without having to depend on conventional treatments, although felt it was impossible to control the eczema without them, considering them to be a 'necessary evil'. ${ }^{11}$ Others have found that patients/carers sometimes receive conflicting advice regarding their safe use from different health professionals. ${ }^{12}{ }^{13}$ Another qualitative study found that parents had unmet information needs, including questions about side effects of topical-corticosteroids and alternatives to topical-corticosteroids. ${ }^{14}$ Further qualitative research that seeks to explore parents/carers' understandings and concerns about using topicalcorticosteroids to help to manage their child's eczema would enable better understanding of the barriers to their use.

The internet has revolutionised our relationship with information. In $2015,86 \%$ of households in Great Britain had internet access and $78 \%$ of people accessed the internet every day or nearly every day. ${ }^{15}$ Online platforms are increasingly being used to communicate with others who have similar health issues. ${ }^{16}$ Online forums are discussion sites that allow users to communicate their personal experiences and engage in interaction with other individuals, through the medium of asynchronous written communication. These forums may provide qualitative researchers with a rich and valuable source of primary, naturalistic data about users' perspectives and experiences of a particular health issue, and may enable analysis of discourses taking place within the online setting. ${ }^{17-19}$ There has been an increase in qualitative research seeking to analyse these data on a wide range of healthrelated conditions. ${ }^{20-23}$

Qualitative research has started to explore the potential impacts of using online forums. Several domains through which patients' online interactions can impact positively and negatively on health have been described, including: finding information; feeling supported; affecting behaviour (others'

This article is protected by copyright. All rights reserved. 
experiences can influence behaviour change); and experiencing health services (navigating services, asking questions of health professionals). ${ }^{24}$ Others have highlighted the importance of online forums in redressing offline knowledge deficits and for modelling behaviours from others in the selfmanagement of long-term conditions. They also highlight the permanence of internet communication, providing a wealth of information available for future forum users. It is therefore particularly pertinent to explore the nature of information being shared in this way. ${ }^{25}$

Qualitative studies of discussions about eczema in online forums can allow valuable insight into forum users' perspectives and experiences, which may complement existing qualitative research. This study aims to explore the understandings and concerns about topical-corticosteroids amongst parents/carers of children with eczema who have posted messages on online forums.

\section{METHODS}

This qualitative study sought to explore messages (and their resultant discussions) about topicalcorticosteroids posted by parents/carers of children with eczema to two UK-based discussion forums.

\section{Data retrieval}

A scoping review of online resources for parents/carers of children with eczema was conducted by one author (EJT) in August 2015 to identify relevant forums. One eczema forum was chosen as the most consistently active forum based in the UK. At the time of the search it had 5,828 postings on 1,233 eczema topics (1,050 postings to the 'eczema in babies and children' section) dating back to 2003. The scoping review also highlighted discussions related to eczema on various parenting forums. A UK-based, general parenting forum with over 14 million visits per month was also chosen to allow a diverse range of perceptions and understandings about topical-corticosteroid use in childhood eczema to be explored.

The researcher familiarised herself with these forums, enabling a search strategy to be devised for each forum. For the parenting forum the internal search function was employed to search for discussions on 'topical steroids'. For the eczema forum, the section on 'Babies and Children' was searched for all discussion threads relating to 'topical steroids'. Searches were conducted in November 2015. To ensure comprehensive and systematic representation of forum discussions, the first 100 search results for each forum were reviewed. Data were collected until saturation was achieved i.e. no new themes emerged. All discussions relevant to the research question were copied

This article is protected by copyright. All rights reserved. 
into Microsoft Word verbatim, assigned a unique ID, and then exported to qualitative data management software Nvivo (version 10) for analysis.

\section{Ethical considerations}

Approval was granted by University of Southampton Faculty of Medicine Ethics Committee in November 2015 (ref: 17457). Debate surrounds the use of online forum messages for the purposes of qualitative data analysis, particularly about perceptions of privacy and the extent to which the messages are considered to be in the public domain. ${ }^{16} 192627$ The approach adopted in this study follows British Psychological Society guidelines ${ }^{28}$ which consider online forum messages to be located within the public domain, provided that no forum registration is required by the researcher to view them. This approach has been widely used in other studies. ${ }^{20-22}$ The online forums involved in this study are freely available to the public and open access (i.e. not password protected); people contributing to the forum discussions can therefore be considered as giving their implicit consent for open access to these discussions. Following the ethics committee's guidance and to protect the anonymity of the data, forums have not been identified and data excerpts have been paraphrased with any identifiable information removed. All authors agreed the adapted paraphrased quotations prior to submission.

\section{Data analysis}

An inductive thematic analysis was conducted to enhance understanding about patient/carer views about topical-corticosteroids for children with eczema. ${ }^{29}{ }^{30}$ Each discussion was read several times and relevant posts coded line by line by one author (EJT). Codes were derived inductively from the data and grouped together to produce an initial coding frame. From this a detailed coding manual was created to ensure transparent and systematic coding of the data. Codes and theme/sub-theme definitions were discussed with, and iteratively developed by, the research team (EJT, MS and IM) to offer diverse inferences and interpretation of the data. Using NVivo enabled a detailed audit trail to be maintained.

\section{RESULTS}

Forum searches yielded 27 discussions relating to topical-corticosteroid use in childhood eczema (17 discussions from the parenting forum and 10 from the eczema forum). These discussions involved 95

This article is protected by copyright. All rights reserved. 
forum users and dated from 2003 - 2015. The discussions were conversational, generally supportive in nature and similar in both forums; although the eczema forum appeared to have greater site moderation (i.e. an employee or forum user who responds to some of the comments or removes spam).

Analysis of parents/carers' discussions about topical-corticosteroids highlighted three themes: 1) diverse beliefs about the use of topical-corticosteroids, 2) uncertainty and confusion about using/applying topical-corticosteroids, 3) seeking to resolve conflicting advice received offline and advice on navigating health services. These themes are explored in detail below. Selected quotes to illustrate each theme and subtheme are presented in Table 1. All quotes are labelled with a participant ID and type of forum ( $E=$ eczema forum, $P$ = parenting forum).

\section{[Insert Table 1]}

\section{Diverse beliefs about the use of topical-corticosteroids}

A range of beliefs were expressed in the forum discussions including beliefs about perceived efficacy, potential side effects and correct usage of topical-corticosteroids. A sense of cautiousness about using topical-corticosteroids for treating childhood eczema was commonly expressed. Many viewed topical-corticosteroids as 'strong', 'harsh', or 'unnatural' products. Some forum users saw topicalcorticosteroids as an ineffective way of managing their child's eczema due to the seemingly transient relief of eczema flare ups that they provided. Terms such as 'rebound' or 'withdrawal' were used, suggesting an overlap with the terminology and concepts of addiction.

A dominant belief about the effects of topical-corticosteroids was that they cause the skin to thin or fade, or reference was made to generalised notions of 'skin damage'. Many forum users expressed great anxiety about applying creams that could potentially cause permanent harm to their child's skin. For some forum users concerns about skin thinning seemed to be influenced by the advice they received from their health professional and other forum users, reinforcing the view that the risks of topical-corticosteroids outweighed the benefits.

Other perceived negative effects of topical-corticosteroids were also explored. In one discussion, some forum users believed that topical-corticosteroids could have an effect on mood and behaviour but other users felt that this was unlikely and more associated with anabolic steroid use. This

This article is protected by copyright. All rights reserved. 
highlights the potential for confusion with other 'steroid' products that are very different from topical-corticosteroids.

Although there appeared to be a general sense of cautiousness, positive views about topicalcorticosteroid use were also expressed. In particular, some expressed a view that topicalcorticosteroids were safe and effective if used correctly and that using topical-corticosteroids provided an increased sense of control over their child's eczema flare ups. Underpinning these more positive views seemed to be the belief that more damage would be done to their child's skin by not trying to control eczema with topical-corticosteroids as it could lead to infection and greater skin damage from scratching. Some forum users offered advice to others, for instance about having to taper off steroid use rather than just stop to prevent more flare ups. Others believed (and advised other forum users) that it is important to continue to treat an eczema flare up for a few days after it has visibly calmed down.

\section{Uncertainty and confusion about using/applying topical-corticosteroids}

The forums seemed to be used by parents/carers asking questions about duration of use, where and when to use creams and expressing confusion about the strength/potency of different creams. A common concern expressed in the forums was about potential over-use of topical-corticosteroids. Uncertainties about the amount of cream to use per application and about using continuous applications but on different/subsequent flare ups were expressed. This seemed to be influenced by doubts about when to stop and how to stop using topical-corticosteroids successfully.

Some forum users expressed uncertainty about where on the body topical-corticosteroids could be safely used and questioned the suitability of topical-corticosteroids for babies and young children and on sensitive areas of the body such as the face. Other forum users were reassured about using topical-corticosteroids on their children's faces if they perceived the creams to be low strength corticosteroids. The perceived potency and variety of different topical-corticosteroid creams seemed to be another source of uncertainty in the online discussions. A common representation in the forum discussions was that a higher percentage topical-corticosteroid cream is more potent, regardless of the active ingredient or type of steroid (i.e. a 2.5\% mild topical-corticosteroid is viewed as more potent than a $0.1 \%$ of a very potent topical-corticosteroid).

This article is protected by copyright. All rights reserved. 


\section{Seeking to resolve conflicting advice received offline and advice on navigating health services}

Another source of concern for parents/carers revolved around their experiences of receiving conflicting advice about topical-corticosteroids in terms of duration, dosage, tapering and safety (sensitive areas, side effects) from different health professionals. People also talked about their experiences of receiving conflicting advice about specific topical-corticosteroid treatments from health professionals compared with product information leaflets and medical websites, in terms of suitability for young children and directions for use. These experiences of conflicting advice contributed to forum users' accounts of uncertainty and caution around topical-corticosteroid use, and seemed to create doubts about the trustworthiness of some professional advice. Forum users sought to resolve these conflicts by asking other forum users for their advice in the hope of getting a 'clear answer' from other parents with experiential expertise.

Related to this, some posts discussed experiences of health services and responded to others' concerns with advice about how to navigate services, for instance reflecting on differing responses from different health professionals, or suggesting requesting dermatology referral from their GP.

\section{DISCUSSION}

Analysis of online discussions about topical-corticosteroid use in childhood eczema highlighted three themes: 1) diverse beliefs about the use of topical-corticosteroids, 2) uncertainty and confusion about using/applying topical-corticosteroids, 3) seeking to resolve conflicting advice received offline and advice on navigating health services. A general sense of cautiousness about topicalcorticosteroids and a wide range of specific concerns were expressed in the forums. There was relatively little awareness about how to access advice regarding best practice in topicalcorticosteroid use for childhood eczema. Many expressed concerns about the perceived short-term or transient effectiveness of topical-corticosteroids with linked concerns about 'rebound' or 'withdrawal' effects. Many forum users also spoke about potential side effects of topicalcorticosteroid use such skin thinning. These findings are consistent with previous research, which highlighted that fears of skin thinning are a common cause for concern around topical-corticosteroid use ${ }^{8-10}$ and that the concept of 'control' rather than 'cure' of eczema is challenging for parents. ${ }^{12}$ Many carers appeared to bring their uncertainties to the forum, asking questions about safety and duration of use, where and when to use creams, and expressing confusion about the strength/potency of different products. This is consistent with a recent meta-synthesis exploring how patient online communities contribute to supporting self-management of long-term conditions,

This article is protected by copyright. All rights reserved. 
which found that people reach out to online communities because of an unmet offline need for information and/or emotional support. ${ }^{25}$ Parents also shared their experiences of receiving conflicting advice from different health professionals, or conflicting advice from professionals compared with product information leaflets and trying to resolve this through asking advice from other forum users. While a general sense of caution about regularly using medicines has been found for many conditions ${ }^{31}$, the specific uncertainties about topical-corticosteroids highlight a need for more detailed information about the different types and strengths of topical-corticosteroids. They also highlight a need for consistent advice from health professionals about safe and effective use, including signposting to accessible high quality information, in order to enable self-management if questions arise after the consultation or clinic visit.

Forum users appeared to value the social support and group identity from online interaction with other parents/carers with similar experiences. It has been observed in online forums for other conditions that users appear to favour the experiential knowledge of perceived 'expert patients' with experience of the condition over the presumed expert knowledge of health professionals. ${ }^{25}$ We found a similar phenomenon of forum users seeking detailed health information from 'expert parents', particularly when they had received conflicting advice in the offline world. This may suggest that the general public no longer consider medical expertise as something that exists solely in health professionals. ${ }^{32}$ Online communities allow users to navigate collective knowledge, which is created through the lived experiences of peers, in accessible language and their convenience. As such, this collective, experiential knowledge of fellow lay people can be viewed as a more useful resource than the medical knowledge of health professionals. ${ }^{25}$

A potential disadvantage of online forums is that the content of messages could be misleading or inaccurate, particularly with regards to medical information, and the potential for negative as well as positive impacts from such online support has been highlighted by others. ${ }^{24} 32$ Forum users are unable to judge the expertise of people giving medical advice on online forums and there is no guarantee that a person claiming to report an experience has actually had that experience. We found examples of useful advice in our data about continuing to treat eczema flare ups after it had visibly calmed down and forum users clearly valued the opportunity to ask questions of other parents. We also found examples of potentially unhelpful advice about skin damage and skin thinning, and seemingly commercially driven advice that promoted expensive, non-evidenced based eczema treatments. The overall impression was of information that would be likely to amplify existing concerns about topical-corticosteroids and, in particular, concerns about skin thinning.

This article is protected by copyright. All rights reserved. 
Nevertheless, online forums function as a powerful site of community for their users and such group identification, as defined by social identity theory ${ }^{33}$, is beneficial to well-being and behaviour. Previous qualitative research on health-related online forums has highlighted the important role that they play in providing the opportunity to receive social support and to learn from and model others' lived experiences. ${ }^{202134}$ Bandura's Social Learning Theory ${ }^{35}$ proposes that people learn from one another by observing, imitating and modelling others' behaviours and the outcomes of those behaviours. Being able to see how others cope with and manage a particular condition can help to validate illness experiences and negate potential offline frustrations. ${ }^{25}$

This study highlights a novel and useful way of exploring people's concerns on a health topic, which can complement primary qualitative research. It is possible that the people who accessed the forums explored in this study had more extreme views and more difficult experiences than others. Data were retrospectively collected so it was not possible to ask parents to expand on or clarify their postings. Being able to clarify and explore further parents/ carers' understandings and concerns of topical-corticosteroids may have generated richer data that would have enabled a more in-depth qualitative analysis. With more time we may have explored other aspects relating to the use of online forums for eczema, for instance exploring emotional support provided within forums.

In conclusion, parents/carers of children with eczema need clear, consistent and detailed information about how to use topical-corticosteroids safely in case questions arise after GP/dermatologist consultation. Given the prevalence of concerns about potential adverse effects of topical-corticosteroids, it would seem prudent to signpost parents/carers towards convenient, consistent, evidence-based information to ensure that the potential negative impacts of seeking (unsubstantiated) medical advice online are minimised. In the absence of such information they are likely to turn to online discussion forums as their sole resource where, although much useful support and advice can be found, some is of questionable validity.

\section{REFERENCES}

1. Hay RJ, Johns NE, Williams HC, et al. The global burden of skin disease in 2010: an analysis of the prevalence and impact of skin conditions. J Invest Dermatol 2014; 134(6):1527-34.

2. Williams $H$, Stewart A, von Mutius $E$, et al. Is eczema really on the increase worldwide? J Allergy Clin Immunol Pract 2008; 121(4):947-54. e15.

This article is protected by copyright. All rights reserved. 
3. Chamlin SL, Frieden IJ, Williams ML, et al. Effects of atopic dermatitis on young American children and their families. Pediatrics 2004;114(3):607-11.

4. Beattie PE, Lewis-Jones MS. An audit of the impact of a consultation with a paediatric dermatology team on quality of life in infants with atopic eczema and their families: further validation of the Infants' Dermatitis Quality of Life Index and Dermatitis Family Impact score. Br J Dermatol 2006; 155(6):1249-55.

5. National Institute for Health and Care Excellence (NICE). Atopic eczema in under 12s: diagnosis and management, December 2007. Avaliable at: https://www.nice.org.uk/guidance/cg57

6. Beattie PE, Lewis-Jones MS. Parental knowledge of topical therapies in the treatment of childhood atopic dermatitis. Clin Exp Dermatol 2003; 28(5):549-53.

7. Santer M, Burgess H, Yardley L, et al. Managing childhood eczema: qualitative study exploring carers' experiences of barriers and facilitators to treatment adherence. J Adv Nurs 2013; 69(11):2493-501.

8. Aubert-Wastiaux H, Moret L, Le Rhun A, et al. Topical corticosteroid phobia in atopic dermatitis: a study of its nature, origins and frequency. Br J Dermatol 2011; 165(4):808-14.

9. Charman C, Williams H. The use of corticosteroids and corticosteroid phobia in atopic dermatitis. Clin Dermatol 2003; 21(3):193-200.

10. Charman CR, Morris AD, Williams HC. Topical corticosteroid phobia in patients with atopic eczema. Br J Dermatol 2000; 142(5):931-36.

11. Nørreslet M, Bissell P, Traulsen JM. From consumerism to active dependence: Patterns of medicines use and treatment decisions among patients with atopic dermatitis. Health 2010;14(1):91106.

12. Santer M, Burgess $H$, Yardley L, et al. Experiences of carers managing childhood eczema and their views on its treatment: a qualitative study. Br J Gen Pract 2012; 62(597):e261-e67.

13. Smith SD, Hong E, Fearns S, et al. Corticosteroid phobia and other confounders in the treatment of childhood atopic dermatitis explored using parent focus groups. Australas J Dermatol 2010; 51(3):168-74.

This article is protected by copyright. All rights reserved. 
14. Gore C, Johnson RJ, Caress AL, et al. The information needs and preferred roles in treatment decision-making of parents caring for infants with atopic dermatitis: a qualitative study. Allergy 2005; 60(7):938-43.

15. Office for National Statistics (ONS). Internet Access - Households and Individuals 2015: Use of the internet by adults in Great Britain including mobile access, activities, shopping, security and storage, 2015. Avaliable at:

http://www.ons.gov.uk/peoplepopulationandcommunity/householdcharacteristics/homeinternetan dsocialmediausage/bulletins/internetaccesshouseholdsandindividuals/2015-08-06

16. Mazanderani F, Powell J. Using the internet as a source of information about patients' experiences. In: Understanding and Using Health Experiences (Ziebland S, Calabrese J, Coulter A, Locock L, eds). Oxford: Oxford University Press, 2013; 94-103.

17. Holtz P, Kronberger N, Wagner W. Analyzing internet forums. J Media Psychol 2012; Vol 24(2):5566

18. Robinson KM. Unsolicited narratives from the Internet: a rich source of qualitative data. Qual Health Res 2001; 11(5):706-14.

19. Seale C, Charteris-Black J, MacFarlane A, et al. Interviews and Internet forums: a comparison of two sources of qualitative data. Qual Health Res 2010; 20(5):595-606 12p.

20. Attard A, Coulson NS. A thematic analysis of patient communication in Parkinson's disease online support group discussion forums. Comput Human Behav 2012; 28(2):500-06.

21. Coulson NS. Sharing, supporting and sobriety: a qualitative analysis of messages posted to alcohol-related online discussion forums in the United Kingdom. J Subst Use 2014; 19(1-2):176-80.

22. Flower A, Bishop FL, Lewith $G$. How women manage recurrent urinary tract infections: an analysis of postings on a popular web forum. BMC Fam Pract 2014; 15(1):1-8.

23. Henderson EM, Rosser BA, Keogh E, et al. Internet sites offering adolescents help with headache, abdominal pain, and dysmenorrhoea: a description of content, quality, and peer interactions. $J$ Pediatr Psychol 2012; 37(3):262-71.

24. Ziebland S, Wyke S. Health and Illness in a Connected World: How Might Sharing Experiences on the Internet Affect People's Health? Milbank Q 2012; 90(2):219-49.

This article is protected by copyright. All rights reserved. 
25. Allen C VI, Kennedy A, Rogers A. Long-Term Condition Self-Management Support in Online Communities: A Meta-Synthesis of Qualitative Papers. J Med Internet Res 2016; 18(3):e61.

26. Eysenbach G, Till JE. Ethical issues in qualitative research on internet communities. BMJ 2001; 323(7321):1103-05.

27. Heilferty CM. Ethical considerations in the study of online illness narratives: a qualitative review. J Adv Nurs 2011;67(5):945-53.

28. Hewson CBT, Brown I, Coulson NS, et al. The British Psychological Society: Ethics Guidelines for Internet-mediated Research. Available at:

http://www.bps.org.uk/system/files/Public\%20files/inf206-guidelines-for-internet-mediatedresearch.pdf

29. Braun V, Clarke V. Using thematic analysis in psychology. Qual Res Psychol 2006; 3(2):77-101.

30. Joffe H, Yardley L. 4. Content and thematic analysis. In: Research methods for clinical and health psychology (Marks DK, Yardley L, eds) California: Sage, 2004; 56-68.

31. Pound $\mathrm{P}$, Britten $\mathrm{N}$, Morgan $\mathrm{M}$, et al. Resisting medicines: a synthesis of qualitative studies of medicine taking. Soc Sci Med 2005; 61(1):133-55.

32. Barker KK. Electronic Support Groups, Patient-Consumers, and Medicalization: The Case of Contested Illness. J Health Soc Behav 2008; 49(1):20-36.

33. Tajfel H, Turner JC. The social identity theory of intergroup behaviour. In: Psychology of Intergroup Relations (Worchel S, Austin WG, eds) Chicago, IL: Nelson-Hall, 1986; 7-24.

34. Tichon JG, Shapiro M. The process of sharing social support in cyberspace. Cyberpsychol Behav 2003; 6(2):161-70.

35. Bandura A. Social learning theory. New Jersey: Prentice-Hall, 1976.

This article is protected by copyright. All rights reserved. 
Box 1: Best practice in topical-corticosteroid use for childhood eczema

Best practice in topical-corticosteroid use for childhood eczema (NICE guideline ${ }^{5}$ )

Topical-corticosteroids should only be used on areas of active atopic eczema (redness or flare-ups), or eczema that has been active within the past $\mathbf{4 8}$ hours, which may include areas of broken skin. Emollients should be used continuously for maintenance (preventing flares).

Potency of topical-corticosteroid should be matched to eczema severity, e.g. mild potency for mild disease, moderate potency for moderate disease, and potent topicalcorticosteroids for short-term use in severe eczema.

Start treatment as soon as signs of a flare appear and to continue for $\mathbf{4 8}$ hours after symptoms subside.

Use is generally in short bursts of 3-5 days to gain control, and for up to two weeks in moderate to severe disease.

On the face and neck, particularly in children, start with a mild topical-corticosteroid, except for short term use (3-5 days) of moderate topical-corticosteroid for severe flares.

Very potent preparations in children should only be used under specialist dermatological supervision. Potent topical-corticosteroids in children under 12 months should only be used specialist dermatological supervision.

If flares are frequent (two or three per month) consider topical-corticosteroids for two consecutive days per week as maintenance treatment once the eczema has been controlled.

This article is protected by copyright. All rights reserved. 
Table 1: Illustrative Quotes by theme

\begin{tabular}{|l|l|}
\hline $\begin{array}{l}\text { THEME } \\
\text { Subtheme }\end{array}$ & Representative Quotes \\
\hline
\end{tabular}

\section{BELIEFS ABOUT TOPICAL-CORTICOSTEROIDS}

Cautious about using topicalcorticosteroids

Topical-corticosteroids are harsh, unnatural products
"I took him to a GP and they couldn't tell me what was making it flare up - she's never had it this bad before. They keep giving me [mild topical-corticosteroid] to use, which I am really not happy about. I am using [emollient] on her in the shower and am smothering her in it 3 times a day, but it doesn't seem to be making any difference" (Parenting forum, P14-3)

"I try to avoid using strong chemicals on my children so all the meds and steroid creams have been a big worry and concern for the whole family. My friend suggested I try using [brand named organic detergent] and skin care products. There's a lot of info on their website about how it can help avoid flare ups. I started using their washing powder and moisturiser which is all organic and natural and has helped loads! It's such a relief not having to use steroids on my children anymore." (Eczema forum, P1-1)

Topical-corticosteroids are only effective in the short-term

Topical-corticosteroids lead to skin thinning

Topical-corticosteroids affect mood
"My little girl (15 months) has this rash that looks like eczema. It's horrible and all over her neck and on her chin. I've tried loads of different creams and nothing helped until I tried steroids... cleared it right up, but the rash came back as soon as I stopped." (Parenting forum, P10-1)

"I've tried loads of different emollients on his legs and nothing helped. The steroids seemed to work but only until I stopped using them and then the eczema comes right back." (Eczema forum P8-1)

"We used [potent topical-corticosteroid] for about a month and a half in the end. Sadly it only worked on the days we were putting it on, but I decided to stop because I was so worried about the side effects it could have. Luckily it didn't damage his skin at all, but I was super worried and for ages I asked every dermatologist we saw to have a look just to be sure!" (Parenting forum, P11-6)

"My baby started getting eczema over the last month or so. My GP suggested [leave on emollient] and I am using loads of it, but I don't think it's doing anything. I asked the GP if there's anything else I can try because I thought it might be worth trying a mild steroid cream but my doctor advised against it because the risks (skin thinning) outweigh the benefits." (Eczema forum, P7-1)

"P1 I was using a [mild topical-corticosteroid] on my 11 month old boy for a few months. During this time he seemed to act more aggressively than usual. I am not using the creams anymore and he seems to have calmed down - has anyone else experienced this?"

P2 Are you worried that this steroid may be affecting his behaviour in the same way that, say, anabolic steroids can? They are very different."

P3 Strong hydrocortisone creams can affect the pituitary gland so I think it's possible they can affect mood, they can also affect the adrenal gland, but I think that is quite rare. I do know people who have had withdrawal symptoms from using [potent topical steroid], which included feeling sick, trembling, , and anxiety so there is clearly some affect on mood. (Parenting forum, P3)

This article is protected by copyright. All rights reserved. 


\begin{tabular}{|c|c|}
\hline $\begin{array}{l}\text { Topical-corticosteroids are safe if } \\
\text { used correctly }\end{array}$ & $\begin{array}{l}\text { "My } 6 \text { year old daughter gets really upset about her eczema. We try to take breaks } \\
\text { from the steroids so only use it for a week or so and then stop for a few days. } \\
\text { You're unlikely to get any skin thinking as long as you are off the steroids as often } \\
\text { as you are using them." (Eczema forum, P8-2) } \\
\text { "My baby girl got eczema all over her body when she was only a few months old. } \\
\text { We are using a mild steroid cream, but I've always thought that it will only cause } \\
\text { problems like skin thinning and things like that if you use strong steroids for a long } \\
\text { period of time. It's better to get the itching under control so it's OK to use it for a } \\
\text { short time in a low dose" (Eczema forum, P7-2) } \\
\text { "My son's had eczema since he was a few months old. We took him to see a } \\
\text { specialist at the hospital, and she gave us a stronger cream (2.5\%) and told us to } \\
\text { use it with emollient and bath oil. The Dr reassured us that it's safe even for babies } \\
\text { and better to react to a flare-up with the cream than to let him itch and scratch, } \\
\text { which can further damage the skin" (Parenting forum, P13-5) }\end{array}$ \\
\hline $\begin{array}{l}\text { Topical-corticosteroids are effective } \\
\text { at relieving eczema flare ups }\end{array}$ & $\begin{array}{l}\text { "My daughter has very bad eczema. I really wasn't happy about using steroids to } \\
\text { start with either. } 7 \text { years later and I am so over that! Now I use anything that helps } \\
\text { to relieve a flare up" (Parenting forum, P12-6) }\end{array}$ \\
\hline $\begin{array}{l}\text { Topical-corticosteroids are effective } \\
\text { if they are tapered off and used } \\
\text { beyond the flare up }\end{array}$ & $\begin{array}{l}\text { "We've been given a strong steroid diluted in petroleum jelly. Apparently they use } \\
\text { this type of topical steroid in a lot of top children's hospitals. We only use it when } \\
\text { needed, for as little time as possible. It's really important to taper your child off } \\
\text { steroid creams or else they'll get flare-ups when they come off it." (Parenting } \\
\text { forum, P11-4) } \\
\text { P2: "Am I supposed to use the [mild topical-corticosteroid] on red skin and then } \\
\text { stop as soon as the skin looks better? I heard somewhere that you should keep } \\
\text { using it for a couple of days after the skin looks better." } \\
\text { P3: "It [mild topical-corticosteroid] will work quicker on new eczema so best to use } \\
\text { it as soon as you spot any new patches. It's also a good idea to use it for one or } \\
\text { two days after the skin looks better to make sure all the layers of skin have healed } \\
\text { and not just the top layer." (Eczema forum, P4) }\end{array}$ \\
\hline \multicolumn{2}{|c|}{ UNCERTAINTY ABOUT TOPICAL-CORTICOSTEROID USE } \\
\hline Uncertainty about duration of use & $\begin{array}{l}\text { "I guess the question is when to use steroids. The doctors always said to only use } \\
\text { them for a few days at a time. When a patch flares up the steroids generally help } \\
\text { within a few days, but then we find that another small patch has flared up } \\
\text { somewhere else on his body so we end up using the cream for ages but in different } \\
\text { places if that makes sense." (Parenting forum, P9-1) } \\
\text { "I've heard load about how steroid creams can harm the skin if you use it wrong. } \\
\text { My question is what is the wrong way to use them? I just don't know if I'm using it } \\
\text { as I'm meant to. My GP just says to use it when the skin is red. I use a fingertip } \\
\text { amount of cream on the worst looking bits and I stop putting the steroids on so } \\
\text { soon as it looks better. I don't use it all over the body. Does that sound right? Is it } \\
\text { ok to use it a couple of days here and there? I really don't want to damage their } \\
\text { skin, but then I don't want it to be sore and itchy either. As soon as I stop the } \\
\text { cream the patches come right back." (Eczema forum, P5-1) }\end{array}$ \\
\hline Uncertainty about topical- & "Our dermatologist has given my 4 month old baby [potent topical-corticosteroid] \\
\hline
\end{tabular}

This article is protected by copyright. All rights reserved. 


\begin{tabular}{|c|c|}
\hline $\begin{array}{l}\text { corticosteroids use in young } \\
\text { children and babies }\end{array}$ & $\begin{array}{l}\text { to use for a couple of weeks, followed then by [moderate topical-corticosteroid] for } \\
\text { another } 2 \text { weeks. What are your thoughts on this? It seems very strong for a baby! } \\
\text { I don't mind using the [moderate topical-corticosteroid], but really nervous about } \\
\text { putting the [potent topical-corticosteroid] on him" (Eczema forum, P6-1) }\end{array}$ \\
\hline $\begin{array}{l}\text { Uncertainty about using topical- } \\
\text { corticosteroids on the face }\end{array}$ & $\begin{array}{l}\text { "Our dermatologist gave us a steroid called [moderate topical-corticosteroid] } \\
\text { ointment to use on our } 6 \text { month old. I've been putting it all over her body and face } \\
\text { for the past five days. We were told to use it as long as the skin is red (it is always } \\
\text { red). No one told not to use it for too long, or to avoid her face. I'm really worried } \\
\text { about it as I don't want to damage her skin. Do you think it's OK to use it on the } \\
\text { face?" (Eczema forum, P5-1) } \\
\text { "We always use steroid creams for flare-ups. It's usually pretty good at clearing the } \\
\text { patches but you need different strength creams for different parts of the body. Our } \\
\text { dermatologist's given us a 1\% strength to use on the face, and [moderate topical- } \\
\text { corticosteroid], which I think is pretty strong, to use on the body." (Parenting } \\
\text { forum, P7-3) }\end{array}$ \\
\hline Uncertainty about steroid potency & $\begin{array}{l}\text { P1: "Can anyone tell me what is meant by a strong steroid? What brand name?" } \\
\text { P2: "My GP's prescribed a } 2 \% \text { cream [combination potent topical-corticosteroid } \\
\text { with antimicrobial] but then my eczema nurse told me to stop using it as soon as } \\
\text { possible. When I asked the dermatologist they said it was fine to use, particularly } \\
\text { on the bad bits. I think that } 2 \% \text { creams are potent, but I think there's even a } 5 \% \\
\text { one. I think [moderate topical-corticosteroid] is very mild." (Parenting forum, P4) }\end{array}$ \\
\hline \multicolumn{2}{|c|}{$\begin{array}{l}\text { SEEKING TO RESOLVE CONFLICTING ADVICE RECEIVED OFFLINE AND ADVICE ON NAVIGATING HEALTH } \\
\text { SERVICES }\end{array}$} \\
\hline $\begin{array}{l}\text { Conflicting advice from } \\
\text { professionals compared with } \\
\text { product information leaflets }\end{array}$ & $\begin{array}{l}\text { "I've just got a new cream for my daughter's eczema from a new dermatologist } \\
\text { and according to the information that came with the cream and websites like the } \\
\text { FDA it should not be used on babies my daughter's age or on sensitive areas such } \\
\text { as her face or nappy area. He told me that the cream has been tested on babies } \\
\text { younger than my daughter with no negative effects. I want to trust him and am } \\
\text { feeling a little bit desperate to 'fix' my daughter, but can he really know better } \\
\text { than the company that produces it or organisations that approve the use of } \\
\text { drugs?" (Parenting forum, P11-1) }\end{array}$ \\
\hline $\begin{array}{l}\text { Conflicting advice from different } \\
\text { health professionals }\end{array}$ & $\begin{array}{l}\text { "I saw this one doctor who said that we should use the [mild topical-corticosteroid] } \\
\text { on red inflamed skin and that we should use [potent topical-corticosteroid] } \\
\text { anywhere where the skin is actually broke. But then I saw another GP who told me } \\
\text { not to use [potent topical-corticosteroid] unless it is really bad because it is so } \\
\text { strong and it would damage the skin. Could anyone please give me a clear answer } \\
\text { about when I should use an emollient, or a mild steroid or a stronger steroid? } \\
\text { (Parenting forum, P12-1) } \\
\text { P1: "A few years ago I saw this one doctor who said that we should use the [mild } \\
\text { topical-corticosteroid] on red inflamed skin and that we should use [potent topical- } \\
\text { corticosteroid] anywhere where the skin is actually broke. But then I saw another } \\
\text { GP who told me not to use [potent topical-corticosteroid] unless it is really bad } \\
\text { because it is so strong and it would damage the skin. But another GP once told me } \\
\text { to use [combination potent topical-corticosteroid with antimicrobial] when it was } \\
\text { really red because it looked infected. Could anyone please give me a clear answer } \\
\text { about when I should use an emollient, or a mild steroid or a stronger steroid? My } \\
\text { husband doesn't like using steroids so it only gets used when I do the creams. Does } \\
\text { that matter?" }\end{array}$ \\
\hline
\end{tabular}

This article is protected by copyright. All rights reserved. 


\begin{tabular}{|c|c|}
\hline & $\begin{array}{l}\text { P6: "If you think your child's eczema is getting worse I would recommend you ask } \\
\text { your GP for a referral to a dermatologist. GPs don't have the time to specialise so } \\
\text { even the best ones just don't have the most up to date information" (Parenting } \\
\text { forum, P12) }\end{array}$ \\
\hline $\begin{array}{l}\text { Seeking advice on referral to } \\
\text { dermatology specialist services }\end{array}$ & $\begin{array}{l}\text { "Should I ask to be referred to the dermatology department? Would they test my } \\
\text { son to see if he has any allergies or would they not do that at his age? I understand } \\
\text { that my son's eczema is not as bad as many of the others on this forum but I just } \\
\text { keep worrying about what the future holds" (Eczema Forum, P4-1) } \\
\text { P1:"I have read lots about how using steroid creams incorrectly can cause skin } \\
\text { damage. Can I enquire... what is the incorrect use of steroid creams? My doctor } \\
\text { says just keep putting it on whenever the skin is red but I don't really know if I am } \\
\text { doing it correctly. } \\
\text { P2: You need to use a steroid cream that is strong enough to provide good control } \\
\text { and have an adequate break before you use it again. You should be able to control } \\
\text { flare ups with } 5 \text { days on } 5 \text { days off or } 10 \text { on } 10 \text { off. If not, then you may need a } \\
\text { stronger steroid cream. Also have you been referred to a dermatologist?? It's well } \\
\text { worth the effort to fight for this." (Eczema forum, P5) }\end{array}$ \\
\hline
\end{tabular}

This article is protected by copyright. All rights reserved. 